\title{
POLA PEMBERDAYAAN LEMBAGA EKONOMI MASYARAKAT SEBAGAI PENDUKUNG \\ PENGEMBANAGN KAWASAN AGROWISATA LATUPPA
}

\author{
ROSMITA A. SARIRA, INDRA KUSDARIANTO, I KETUT PATRA
}

\begin{abstract}
ABSTRAK
Industri kepariwisataan merupakan salah satu industry yang mampu menggairahkan perekonomian masyarkat. Daerah - daerah yang maju industri pariwisata akan berdampak pada peningkatan pendapatan masyarakatnya. Keberadaan industri pariwisata disuatu daerah dipengaruhi oleh banyak factor, dua di antaranya adalah regulasi pemerintah daerah setempat yang mendukung investasi di bidang keparawisataan dan potensi sumber daya dimiliki daerah tersebut. Sebagaimana diketahui bahwa kondisi alam Indonesia memiliki potensi penomena alam yang indah.

Penelitian tentang Pola Pemberdayaan Lembaga Ekonomi Masyarakat Sebagai Pendukung Pengembanagn Kawasan Agrowisata Latuppa bertujuan untuk mengetahui peranan lembaga ekonomi masyarakat dalam mendukung kawasan agrowisata Latuppa dan peningkatan pendapatan masyarakat.

Adapun metode analisis yang digunakan dalam indentifikasi tersebut adalah SWOT. Kerangaka SWOT adalah sebuah matrik dua kali dua. Metode yang digunakan untuk mengukur pengaruh keberadaan lembaga ekonomi terhadap pendapatan masyarakat dikasan agrowisata dapat dihitung dangan menggunakan metode analisis regresi sederhana.

Dari hasil penelitian menunjukkan bahwa peranan lembaga ekonomi masyarakat dalam pengembangan kawasan agrowisata belum optimal, oleh karena itu diperlukan starategi utama yaitu menggunakan beberapa kekuatan (strength) guna menangkap peluang (opportunity) ya ng ada. Serta secara umum pendapatan masyarakat sangat dipengaruhi oleh keberadaan lembaga ekonomi yang ada.
\end{abstract}

Kata kunci: Lembaga ekonomi, kawasan agrowisata, pendapatan masyarakat.

\section{Pendahuluan}

\section{Latar Belakang}

Industri kepariwisataan merupakan salah satu industry yang mampu menggairahkan perekonomian masyarkat. Daerah - daerah yang maju industri pariwisata akan berdampak pada peningkatan pendapatan masyarakatnya.

Keberadaan industri pariwisata disuatu daerah dipengaruhi oleh banyak factor, dua di antaranya adalah regulasi pemerintah daerah setempat yang mendukung investasi di bidang keparawisataan dan potensi sumber daya dimiliki daerah tersebut. Sebagaimana diketahui bahwa kondisi alam Indonesia memiliki potensi penomena alam yang indah. 
Secara regional wilayah Luwu secara keseluruhan (kabupaten Luwu, Kota Palopo, Kabupaten Luwu Utara dan Kabupaten Luwu timur) merupakan daerah penghasil buah buahan dan produk pertanian lainnya.

Produksi hasil pertanian khususnya tanaman horticultural berupa buah - buahan cukup potensial untuk di jadikan sebagai salah satu objek wisata, khususnya di Kelurahan latuppa, Kelurahan Murate dan Kelurahan Peta. Jalur pemasarannya juga sederhan, yaitu dari petani kepada pedagang pengupul kemudian konsumen.

Modal, kuantitas dan kualitas Sumberdaya manusia yang belum memandai merupakan dua dari beberapa factor yang menjadi penghambat kurangnya motovasi masyarakat dalam melakukan peningkatan nilai tambah dari produk - produk pertanian yang mereka. faktor penghambat tersebut sesungguhnya dapat dikendalikan dengan membangun keterpaduan kerja antara kelompok - kelompok masyarakat melalu lembaga ekonomi local.

Pemerintah Kota Palopo melalui Dinas Kebudayaan dan Parawisata saat ini telah merancang sebuah konsep yang menjadikan Kelurahan Latuppa, Kelurahan Mungkajang dan Kelurahan Peta sebagai daerah pengembangan agrowisata di kota Palopo. Tujuan Penelitian ini adalah untuk mengetahui peranan lembaga ekonomi masyarakat dalam mendukung kawasan agrowisata Latuppa dan peningkatan pendapatan masyarakat.

\section{Metode Penelitian}

\section{Lokasi Penelitian}

Penelitian ini dilaksanakan di 3 kelurahan yang menjadi wilayah pembangunan Agrowisata Latuppa yang meliputi Kelurahan Latuppa, Kelurahan Murante dan Kelurahan Peta.

Jenis dan Suber Data
(a)Data Primer
(b)Data Sekunder 


\section{Metedo Pengumpulan Data}

Metode pengumpulan data yang digunakan yaitu: (a) Pengamatan yaitu mengumpulkan data melalui pengatan langsung terhadap objek penelitian, dalam hal ini jenis - jenis lembaga ekonomi masyarakat setempat, (b) Wawancara yaitu mengadakan tatap muka langsung dengan responden untuk mengumpulkan data dan informasi yang diperlukan dangan menggunakan pedoman wawancara terstruktur (kuesioner) yang telah disiapkan. Wawancara yang dilakukan untuk mengetahui lembaga ekonomi yang ada dalam mendukung kegiatan pengembangan Kawasan Agrowisata Latuppa, (c) Dokumentasi yaitu mengumpulkan data dengan cara mencatat data - data yang sudah tersedia (dalam bentuk barang cetakan maupun gambar) pada instansi yang terkait dengan pengembangan Kawasan Agrowisata Latuppa.

\section{Metode Analisis Data}

Metode analisis yang digunakan dalam indentifikasi tersebut adalah SWOT. Kerangaka SWOT adalah sebuah matrik dua kali dua, digambarkan dalam table sebagai berikut:

Tabel 3.1Matrik Analisis SWOT

\begin{tabular}{|l|l|l|}
\hline $\begin{array}{l}\text { Kondisi Lingungan } \\
\text { Strategis }\end{array}$ & Kekuatan (S) & Kelemahan (W) \\
\hline Peluang (O) & $\begin{array}{l}\text { Stategi S-O kekuatan } \\
\text { Gunakan peluang } \\
\text { untuk meraih pelarategi W-O }\end{array}$ & $\begin{array}{l}\text { Starasi kelemahan untuk } \\
\text { meraih peluang }\end{array}$ \\
\hline Ancaman (T) & $\begin{array}{l}\text { Stategi S-T kekuatan } \\
\text { Gunakan mengatasi } \\
\text { untuk } \\
\text { ancaman }\end{array}$ & $\begin{array}{l}\text { Strateg W-T } \\
\text { Atasi kelemahan untuk } \\
\text { mengatasi ancaman }\end{array}$ \\
\hline
\end{tabular}

Metode yang digunakan untuk mengukur pengaruh keberadaan lembaga ekonomi terhadap pendapatan masyarakat dikasan agrowisata dapat dihitung dangan menggunakan metode analisis regresi sederhana dengan tahapan analisis sebagai berikut:

1. Tahapan pertama dengan rumus $\mathrm{y}=a+b x$ dimana $b=\frac{\mathrm{n} \sum \mathrm{xy}-\sum \mathrm{x} \sum \mathrm{y}}{\mathrm{n} \sum \mathrm{x} 2-\left(\sum_{\mathrm{x}}\right) 2}$ dan $\mathrm{a}=\frac{\sum \mathrm{y}}{n}-\mathrm{b}\left(\frac{\sum n}{n}\right)$

2. Tahapan kedua mencari nilai Korelasi Linear sederhana dengan rumus $\mathrm{R}=\frac{\sum \mathrm{y}-\sum \mathrm{xy}}{\sqrt{n \sum_{x} 2-}\left(\sum_{x}\right) 2 \sqrt{n} \sum_{y} 2-\left(\sum_{y}\right) 2}$ 


\section{Hasil Penelitian Dan Pembhasan}

Tabel 4. 15

Analisis Regresi Sederhana dari Pengaruh Keberadaan Lembaga Ekonomi terhadap Pendapatan Masyarakat pada Kawasan Agrowisata Latuppa

\begin{tabular}{|l|l|l|l|l|l|}
\hline TAHUN & $\begin{array}{l}\text { LEMBAGA } \\
\text { EKONOMI (X) }\end{array}$ & PENDAPATAN (Y) & $\mathrm{X}_{2}$ & $\mathrm{Y}_{2}$ & $\mathrm{XY}$ \\
\hline 2006 & 3 & 1.625 .000 & 9 & 2.640 .625 .000 .000 & 4.875 .000 \\
\hline 2007 & 3 & 1.625 .000 & 9 & 2.640 .625 .000 .000 & 4.875 .000 \\
\hline 2008 & 3 & 1.625 .000 & 9 & 2.640 .625 .000 .000 & 4.875 .000 \\
\hline 2009 & 4 & 1.735 .000 & 16 & 3.010 .225 .000 .000 & 6.940 .000 \\
\hline 2010 & 4 & 1.725 .000 & 16 & 2.975 .625 .000 .000 & 6.900 .000 \\
\hline JUMLAH & 17 & 8.335 .000 & 59 & 13.907 .725 .000 .000 & 28.465 .000 \\
\hline
\end{tabular}

Berdasarkan Tabel 4.15 diatas maka selanjutnya dilakukan pengetahuan terhadap nilai regresi sederhana (y) dan nilai korelasi (R) dengan tahapan penyelesain sebagai berikut:

$\mathrm{B}=\frac{n \sum x y-\sum x \sum y}{n \sum x^{2}-\left(\sum x\right)^{2}}$

$=\frac{5(28.465 .000)-(17)(8.335 .000)}{5(59)-(17)^{2}}$

$=\frac{142.325 .000-141.695 .000}{295-289}$

$$
=\frac{630.000}{6}
$$

$\mathrm{B}=105.000$

$\mathrm{a}=\frac{\sum y}{n}-\mathrm{b}\left(\frac{\sum x}{n}\right)$

$=\frac{5(28.465 .000)}{5}-(105.000)\left(\frac{17}{5}\right)$

$=1.667 .000-(105.000)(3,4)$

$$
=1.667 .000-357.000
$$

$\mathrm{a}=1.310 .000$

$y=a+b x$

$$
=1.310 .000+105.000 \mathrm{x}
$$

Berdasarkan hasil perhitungan diatas maka dapat dinyatakan bahwa pengaruh keberadaan lembaga ekonomi terhadap pendapatan masyarakat .

Sebagai mana dilihat pada gambar 4.2 diatas menunjukkan bahwa jika lembaga ekonomi tidak ada maka pendapatan rata - rata masyarakat adalah Rp 1.310.000.- . Sedangkan nilai pendapatan yang mempengaruhinya sebesar Rp 105,000 , - Artinya tiap - tiap kenaikan pendapatan masyarakat sebesar $\mathrm{Rp} 1.000 .000$,- dipengaruhi oleh pendapatan Lembaga Ekonomi Masyarakat sebesar Rp 105.000,- Sesuai data dan hasil pengamatan di lapangan antara Tahun 2006 - 2008 jumlah lembaga ekonomi yang ada sebanyak 3 unit dan memberikan pendapatan rata - rata masyarakat setempat sebesar Rp 1.625.000,- . Selanjutnya pada Tahun 2009 - 2010 jumlah lembaga ekonomi menjadi 4 unit yang berpengaruh pada pendapatan rata - rata masyarakat sebesar Rp 1.730.000,-. Hal menunjukkan bahwa keberadaan 
lembaga ekonomi tersebut memberikan pengaruh positif dengan adanya peningkatan pendapatan masyarakat, mesikipun kenaikannya tidak terlalu signifikan.

Guna mengetahui sebesar pengaruh keberadaan lembaga ekonomi tersebut terhadap pendapatan masyarakat, maka dihitung sebagai berikut:

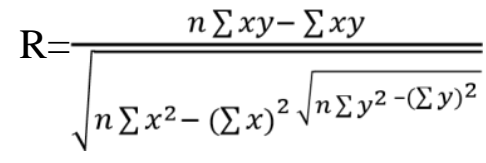

$$
\begin{aligned}
&=\frac{5(28.465 .000)-(17)(8.335 .000)}{\sqrt{5(59)-(17)^{2} \sqrt{5(13.907 .725 .000 .000)-(8.333 .000)^{2}}}} \\
&=\frac{142.325 .000-141.695 .000}{\sqrt{295-289 \sqrt{69.538 .000 .000-69.472 .225 .000 .000}}} \\
&=\frac{630.000}{\sqrt{6 \sqrt{66.400 .000 .000}}} \\
& \mathrm{R}=0,998 \text { atau } 99,8 \% \quad=\frac{630.000}{631.320,83} \\
& R^{2}=(0,998)^{2} \quad \text { atau } 0,996 \text { atau } 99,6 \%
\end{aligned}
$$

Berdasarkan pencapain persentase dari nilai korelasi (R) diatas maka di ketahui bahwa hubungan antara lembaga ekonomi dengan pendapatan masyarakat sebesar 0,998 atau 99,8\% artinya ada hubungan yang sangat kuat antara lembaga ekonomi dengan pendapatan masyarakat. Hubungan yang dimaksud adalah peningkatan pendapatan petani pada kawasan agrowisata Latuppa dipengaruhi oleh jumlah lembaga ekonomi yang ada. Penambahan jumlah lembaga ekonomi dapat meningkat pendapatan masyarakat setempat. Adapun nilai determinasi $\left(R^{2}\right)$ dapat diartikan bahwa keberadaan lembaga ekonomi berpengaruh terhadap pendapatan masyarakat sebesar 99,6\%, sedangkan variable (mata pencaharian) lainnya hanya berpengaruh sebesar $0,42 \%$. Dengan demikian maka keberadaan lembaga ekonomi masyarakat yang ada saat ini dapat memberikan peluang pendapatan masyarakat sekitar.

Perkembangan agrowisata sangat terkait erat dengan kelestarian lingkungan yang ada disekitarnya, sehingga upaya pelestarian lingkungan merupakan hal yang mutlak dilakukan dan bersinergi dengan kegiatan pengembangan kawasan wisata tersebut.

\section{Penutup}

Kesimpulan penelitian ini adalah: (a) Peranan lembaga ekonomi masyarakat dalam pengembangan kawasan agrowisata belum optimal, oleh karena itu diperlukan starategi utama yaitu menggunakan beberapa kekuatan (strength) guna menangkap peluang (opportunity) yang ada. (b) Secara umum pendapatan masyarakat sangat dipengaruhi oleh keberadaan lembaga ekonomi yang ada. Adapun saran dari penelitian ini adalah: (a) Pengembangan kawasan agrowisata Latuppa perlu mendapatkan dukungan dari keberadaan lembaga ekonomi masyarakat setempat, agar kawasan ini dapat bermanfaat yang positif terhadap masyarakat, (b) 
Peneliti ini belum menelan lebih jauh tantang apa penyebab dari tidak berkembangnya lembaga ekonomi masyarakat yang berhubungan langsung dengan kegiatan keparawisataan, sehingga hal ini masi perlu pendalaman pada penelitian - penelitian selanjutnya.

\section{Dafatr Pustaka}

Anonim, Surat Keputusan Bersama Menteri Pertanian dan Menteri Pariwisata,

Pos, dan Telekomunikasi Nomor: 204/KPTS/HK/050/4/1989 dan Nomor KM.47/PW.DOW/MPPT/89 Tentang Pengembanga Wisata Agro.

Anonim, Peraturan Pemerintah Nomor 28 Tahun 2008 tentang Rencana Ruang Wilayah Nasional

Anonim, Undang - Undang RI Nomor 10 Tahun 2009 tentang Keparawisataan

Antara, M, (2009), Dampak Penggadaan Usaha Kecil Sektor Pariwisata

Terhada Pertumbuhan Perekonomian Bali: Suatu Pendekatan

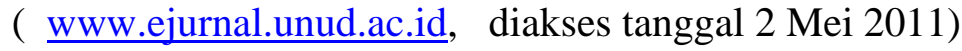

Ashari, (2006), Potensi Lembaga Keuangan Mikro (LKM) dalam Pembangunan Ekonomi Pedesaan dan Kebijakan Pengembangannya, Buletin

KebijakakPertanian Volume 4 No. 2 Juni 20006 : 146 - 164.

Departemen Pertanian RI, (2003), Strategi Pengembangan Wisata Agro di

Indnesia (www.databese.deptan.go.id, diakses tanggal 10 mei 2011)

Harun, R, (2008), Trik Megelolah Daerah Wisata (www.kabarindonesionline. com), diakses tanggal 10 mei 2011)

Karim, S. A, (2009), Strategi Pengembangan dan Pemasaran Parawisata di Daerah Kuranga Berkemban (www.wisatamelayu.com diaksese tangga 10 Mei 2011)

Pamulardi, B (2009), Tesis Pengembangan Agrowisata Berwawasan Lingkungan (Studi Kasus Desa Wisata Tingkat Salatiga),Program Magister Ilmu Lingkungan Program Pascasarjana Universitas Diponegoro Semarang.

Pusat Litbang Agroklimat, (2002), Agrowisata Meningkatkan Pendapatan Petani (www.database.deptan.go.id, diakses tanggal 3 mei 2011) 
Sastrayuda, G.S, (2010), Konsep Pengembangan Agrowisata (www.file upi,ude , Diakses tanggal 3 Mei 2011)

Sekretariat Jenral Deptan, (2009), Wisata Agro Idonesia ; Potensi Bisnis Berbaisis Ekonomi Kerakyatan (Berita Pertanian On-line, diakses tanggal $11 \quad$ Mei 2011)

Sindyreta, (2010),Mengembangkan Agrowisata (www.sindy'sassingmentblogspot. com, diakses tanggal 3 mei 2011)

Tuwo, A, Prof. Dr. Ir. DEA, (2011), Pegelolaan Ekowisata Pesisir dan Laut ; Pendekatan Ekologi, Sosial Ekonimi dan Kelembagaan dan Sarana Wilayah, Penerbitan Brilian Internasional, Jawa Timur.

Utama, I G.B.R, (2008), Agrowisata sebagai Parawisata Alternatif (www.amikom. Ac.id, diakses tanggal 3 Mei 2011)

Word Wildlife Fund - Indonesia, (2009), Prinsip dan kriteria Ekowisata Berbasi Masyrakat, Kerjasma Direktorat Produk Parawisata Ditjen Pengembnag Destinasi Wisata dan WWF - Indonesia Jakarta. 